Theme Article

\title{
Development of a portal to Texas history
}

\author{
Cathy Nelson Hartman, Dreanna Belden, Nancy K. Reis, Daniel Gelaw Alemneh, and Mark \\ Phillips \\ University of North Texas Libraries, Denton, Texas, USA, and \\ Doug Dunlop \\ University of Central Florida Libraries, Orlando, Florida, USA
}

\begin{abstract}
Purpose - To help information professionals learn about issues and considerations in portal building.

Design/methodology/approach - The University of North Texas Libraries' Portal to Texas History provides long-term storage and access to digital copies of important original materials illuminating Texas's past. This paper describes the development of the Portal technology and content - presenting objectives, processes, and future plans - and defines the larger goal of facilitating collaboration among resource-holding institutions.

Findings - Practical aspects of creating and populating the portal include development of specifications and standards, construction of an application framework, selection of content, production of metadata, and refinement of user interfaces. Planned future enhancements to the Portal will augment sustainability and provide added value for users. The portal project may also serve as a catalyst for wider collaborative efforts in digitization.

Originality/value -- The Portal to Texas History project's experiences described in this paper will inform other stakeholders seeking to develop innovative uses of Portal technologies.

Keywords: Portals, Digital storage, Content management, Digital libraries, History, United States of America

Paper type: Case study
\end{abstract}

\section{Introduction}

Texas history can thrill us with its bigger-than-life heroes and heroines, champions, charlatans and rogues. Who can forget the bravery of the defenders of the Alamo or the shenanigans of Jim Hogg? Filled with life, Texas history holds the rich potential to enchant school children and captivate learners of all ages.

Imagine - a school child in Pampa, Texas, reads William Barret Travis' last-ditch pleas from the Alamo, breathing new life into the cry, "Victory or death!" A historian in Marshall, Texas, carefully peruses Anson Jones' memoranda and official correspondence as the last president of the Republic of Texas in preparation for publishing a scholarly article. A school teacher in Dallas prepares material for her students covering pioneering African-American Texas Senators, George T. Ruby, Matt Gaines, and Walter Burton. At the University of North Texas Libraries' 
(UNTLs) Portal to Texas History, the dream of providing unique online historical content is becoming reality.

\section{Beginnings of the Portal}

In 2002, the Portal to Texas History existed only as an idea in the minds-eye of a forwardthinking University of North Texas (UNT) librarian who envisioned the portal as an entry point on the web for access to digital copies of important original materials that could illuminate Texas's past. Digital representations of documents, letters, journals, maps, photographs, artifacts, and other materials could be presented to a much larger audience than the original objects, while helping to preserve the materials through reduced handling. In addition, the UNT Libraries hoped to form partnerships with schools, other libraries, museums, publishers, and individuals to provide access to these materials through the portal. UNT could also offer optional services to partners such as hosting their electronic collections on the portal, providing mentoring services for persons beginning first-time digital projects, and coordinating funding for the collaborative project.

A steering committee consisting of librarians, programmers, teachers, subject specialists, and designers gathered information, examined existing software, and decided how the portal could be constructed to serve its constituents. UNT planned to create technology systems and standards for the project with emphasis on the necessity of preserving the site for long-term usage. After preparing technical specifications (http://texashistory.unt.edu/tech specs.html), UNT secured grant funding, and then selected Index Data Systems of Denmark to implement an open-source software package to structure the portal.

Now in its beta version, the portal is available on the Worldwide web (http://texashistory.unt.edu/). As the portal staff members continue to refine its functionality, they are entering text, images, and descriptive metadata. Development of new content with our partners continues to bring exciting new material for users of the portal.

\section{Goals of the portal}

The portal project is being developed in two phases. Phase one, which is nearly complete, encompassed four objectives: building a technical structure for the portal services, designing a search interface that embraced both beginning and skilled researchers, creating standards and best practices guidelines - including the design of training modules to educate library and museum staff who lack knowledge of the digitization process, and implementing an evaluation plan.

Objective one. Creating the technical structure and the project services for the Portal to Texas History involved two elements. First, a two-server configuration with expanded system storage and with a sophisticated application framework was planned for the technical structure of the site. The application framework supplies file management capabilities, allows search and retrieval of files, enables harvesting of files from collaborating sites for indexing and preservation purposes, allows Z39.50 interoperability with other servers including the Library of Texas Project (http://libraryoftexas.org/), and creates backup copies of all files on a regular 
basis. Administrative functions allow the project administrator to enable pass-worded access for collaborators at distant sites for purposes of data entry. Second, a portable digital imaging unit, comprising a high-end laptop, a scanner, and a digital camera setup, was purchased to assist with on-site training and scanning activities in libraries and museums. After training, small libraries and museums without access to digital imaging hardware and software will be able to borrow the portable equipment.

Objective two. Project staff created standards and best practices guidelines for the portal project and services, and designed and tested a training module that assists with imparting knowledge contained in the project standards and guidelines to persons in museums and libraries. Project standards include element sets for both descriptive and preservation metadata. The "descriptive" metadata delineate the historical items that are digitized and allow searchers to discover and view the materials contained in the digital collections. The "preservation" metadata maintain reference, context, provenance and fixity information about the files, and technical information about file creation, size, and location, software used to create the file, and preservation activities, which will aid the long-term maintenance and viability of digital files. A standardized element set simplifies data entry and ensures that important information is recorded. Best practices guidelines recommend appropriate processes for digital imaging of various types of materials and artifacts. By following best practices guidelines to preserve long-term access to the electronic files, project participants will help ensure that delicate materials will not require repeated handling and re-scanning in the future.

Objective three. The portal web site embraces both beginning and skilled researchers - guiding them through the process of searching for and retrieving relevant information. In addition, Texas historians will contribute original, supplementary materials to offer guidance for diverse users and to highlight subjects of particular interest.

Objective four. The Portal to Texas History contracted with Dr William E. Moen of the Texas Center for Digital Knowledge to create and implement an outcomes-based evaluation plan for the first phase of the project and, additionally, to write a similar plan for evaluation of the second phase of the project. The evaluation plan examines three objectives: creating the technical structure of the portal; creating standards and best practices; and developing the portal web site to guide researchers. The plan focuses on the milestones required to meet objectives: key activities, output (results), outcomes (possible benefits), indicators, and the data sources or methods used to gather evaluative data. The plan also includes questionnaires for collaborators, digital imaging students, young scholars, and researchers, which assess and measure the effectiveness of the metadata, best practices and standards for digitization, training for the application framework, and usability of the web site. Questionnaires will be implemented at appropriate benchmarks in the project.

Phase two objectives continue in development. The four goals of phase two include construction of an online Thesaurus for Texas History, design of a training program for the application framework to be used in a test-bed project with member institutions, establishment of a business plan for cost recovery initiatives, and development of additional content and 
curriculum guides that fulfill the needs of educators teaching Texas history to schoolchildren. These phase two objectives are discussed in more detail later in the article.

\section{Portal processes \\ Selection criteria}

Considering the bourgeoning volume and heterogeneity of information on the web, selection and appraisal of resources for digitization is one of the most difficult tasks in the digital resources management life cycle. Under current criteria, materials selected for the portal should focus on aspects of Texas history of interest to historians, students and lifelong learners - emphasizing materials that are of key importance to Texas history, as well as meagerly documented topics that could benefit from increased access. Selected items should also provide geographic coverage throughout the State of Texas, hold unique or intrinsic value as historical objects, and not duplicate previously digitized material. Copyright is also an issue, and materials can be used only if copyright has been cleared; i.e. the copyright has expired, or the contributing institution has obtained copyright release or owns the copyright.

\section{Metadata framework}

Since its first conceptual description in the First Monday peer-reviewed e-journal almost two years ago (Alemneh et al., 2002), the University of North Texas Libraries' (UNTL) metadata system has continued to evolve. Considering the very dynamic nature of digital resources, the needs and requirements of resource management systems must change over time. Accordingly, the project team adapts the UNTL metadata system for various uses and applications and continues to add important process functionalities such as a graphical user interface for system administrators, content developers, metadata creators, and end-users. Moreover, as the team gains practical experience in describing objects with metadata, it will provide further definition of the elements, and produce local practice guidelines.

The UNTL metadata element set comprises Dublin Core-based descriptive metadata (http://dublincore.org) and detailed technical and preservation information recording how digital resources (text, image, audio, video) are identified, created, formatted, arranged in relevant software applications, and sustained with application of appropriate preservation procedures. User guidelines provide detailed information and assistance to metadata creators. The most current and comprehensive documentation about the UNTL metadata is available on the Worldwide web (http://texashistory.unt.edu/project documents.htm).

The UNT Libraries are now implementing the metadata system. Among other activities to facilitate implementation, the project team has developed metadata crosswalks. Mapping facilitates large-scale collaboration and fosters interoperability among various metadata schemas. The crosswalks will also enable UNT staff to import metadata records directly from participating institutions in a variety of formats, including harvesting metadata from existing MARC (Machine-Readable Cataloging) records.

Early implementation activities revealed some issues. Balancing the specificity of the information that can be represented in and queried from metadata with the cost of producing records continues to prove challenging. In this regard, UNT is automating several aspects of the 
metadata creation process, while monitoring emerging technologies for harvesting technical metadata, as well as related initiatives such as the Research Libraries Group (RLG) led project of Automatic Exposure (www.rlg.org/en/page.php?Page ID=2681). Also at issue is quality control for descriptive metadata to ensure that we satisfy the needs of users, for example, authority control for individual and corporate names and place names. A well-developed thesaurus for the subject area could assist such quality control efforts.

The design of the portal architecture supports the automatic metadata extraction process. Technical information can be captured in the scanning process and harvested automatically when digital objects are transferred into the archive. For instance, scanning specifications are recorded in TIFF (Tagged Image File Format) headers during the scanning process, and that data is then automatically harvested and recorded in the appropriate metadata fields.

Continuing metadata development and application challenges will be met through monitoring and participating in national and international discussions and standards development. UNT is an active member of various statewide, national and international professional associations and consortia related to digital library development. Portal team members participate in standards building activities such as the PREMIS (Preservation Metadata: Implementation Strategies) group (www.oclc.org/research/projects/pmwg/) sponsored by RLG and OCLC (Online Computer Library Center). Also, working in collaboration with the Texas Center for Digital Knowledge (www.txcdk.org/), the UNT School of Library and Information Sciences (www.unt.edu/slis/), and many other partners in Texas libraries, museums, and archives, the UNT Libraries are experimenting with various strategies to meet the challenges of digital resource management. The UNT Libraries currently provide assistance and guidance for small libraries and museums by identifying standards and "best practices" for digital collection management and by coordinating projects and services that participant institutions need, but cannot develop individually.

\section{Portal architecture}

The following sections describe the architecture of the portal from data input through archiving to user access. Figure 1 shows, in a graphical format, the steps involved.

\section{Application framework}

The portal is based on open-sourced initiatives such as XML (Extensible Markup Language), PHP (PHP Hypertext Preprocessor), and XSLT (Extensible Style sheet Language Transformations), as well as various libraries for the conversion of images. The foundation of the portal is the metadata record itself. Each metadata record consists of an individual XML file. This XML file uses a schema developed by the University of North Texas Libraries (UNTL) Digital Projects Department, based on the UNTL metadata element set (http://texashistory.unt.edu/guides/help/UNTL-Metadata-Guide.htm). The schema also introduces some of the program-specific data into the record so that the system is selfcontained in these records. After a call has been made from the system to access the information held in the XML record, XSLT is used to transform the metadata record into the desired output format. 


\section{Hardware}

The portal exists on a Debian distribution of Linux running on two high-end Compaq servers with one acting as a hot backup. Consistent with the project's commitment to open-source software, the portal runs Apache as the web server. Apache has been adjusted to allow for better support of XML and XSLT for the display of data from the portal. The archival system is currently running on an XP box, but has the ability to run on any platform due to the fact that it has been written in Java. The archival system will allow for the management of the rich digital master files on current or future archival media.

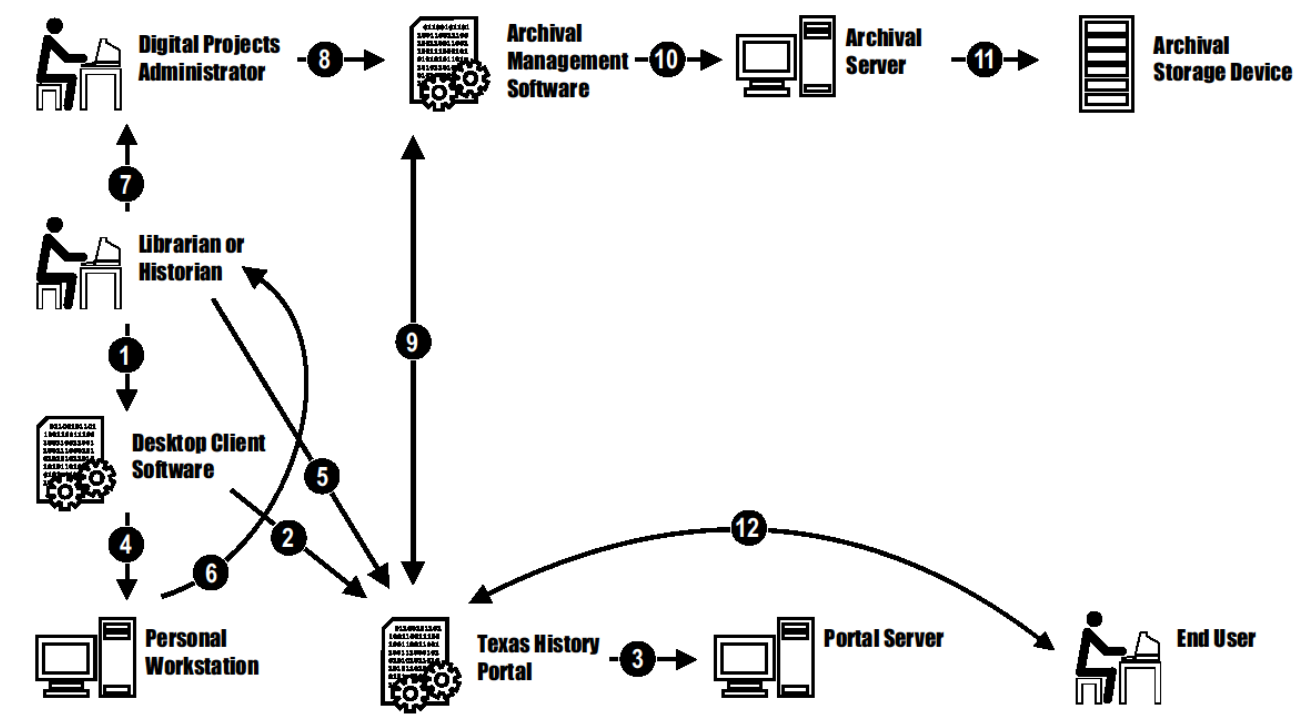

1. The content creator uses the Desktop Client to process the original Digital Master files.

2. The Client creates metadata records containing the technica information about the Digital Masters. It uploads these, as well as web-viewable derivatives of the Masters to the Texas History Portal.

3. The Portal indexes the new metadata record, and stores the web-viewable files for later retrieval.

4. The Client archives the Digital Master files and saves them to disk.

5. The content creator uses a web interface on the Portal to fill in non-technical (descriptive) metadata for the uploaded record.

6. The content creator retrieves the archived Digital Master files.

7. The content creator sends the archived Digital Master files to the Digital Projects Administrator.
8. The Administrator sends the archived Digital Masters to the Archival Management Software.

9. The Archival Management Software extracts the Digital Master files and contacts the Portal to retrieve technical information about the files. File fixity is checked against precalculated values at this point. If the file integrity has been compromised, the Administrator is alerted.

10. The Digital Masters are stored on the Archival Server pending long-term storage.

11. The Archival Server transfers the new Digital Master files to the Archival Storage Device for permanent storage.

12. The End User is able to access the Texas History Portal to search and browse the holdings, and to view the web-viewable versions of the content. The End User may make arrangements with the Administrator to access the Digital Masters if needed.

Figure 1. Texas history portal architecture

\section{Metadata entry mechanisms}

Metadata entry on the portal is facilitated by various administration screens that are created by Xforms, a program designed by Index Data to read an XML schema and output an HTML 
(Hypertext Markup Language) form based on that schema. The metadata entry form contains sections for both descriptive and preservation metadata, and the contents may be edited as needed.

The portal project staff also created in-house a portal client interface program. Developed with the Imagemagick libraries and written in $\mathrm{C}$, the client allows content creators throughout the state to add information to the portal in a unified way. The client is used in conjunction with the digital master files so that there is a consistency in the collection of technical metadata and 50 information and in the creation of web-viewable derivative images. The client automates these tasks, which are labor intensive for the content creators. The client interface obtains a unique identification number from the portal and creates submission packages of the web-viewable files and metadata records, as well as archival file submission packages. Both the metadata and web-presentable files are sent to the portal through HTTP and the archival files are sent either by FTP (File Transfer Protocol) or by mail on DVD (Digital Versatile Disc) or Firewire drives.

\section{Digital archive interface}

The digital archive system functions as an application separate from the portal, but it uses information contained within the portal to complete its tasks. The archival system takes archival packages created by the client tool and unwraps them for ingestion into the archival system. The files are unpackaged, and then their integrity is verified by comparing them against the fixity information stored in the portal metadata records. Confirmed files are then prepared for ingestion into the storage area of the archive. The files are renamed to ensure uniqueness across the system. The archival software is designed so that it functions independently of the storage mechanism, allowing the system to easily adjust as changes in technology occur. At regular intervals, the archival system checks the fixity of the files on the storage devices and alerts the portal administrators to any problems that might arise.

\section{Public interface}

Users access the portal through a web-based interface that allows both browsing and searching. Queries may be phrased using natural language or Boolean operators. Queries initiated from the Young Scholar's page search only the descriptive metadata, while queries from the Researcher's page search both full-text, when available, and metadata. Additional filters control classroom and teacher access to parts of the web site that provide curriculum guides and enable online class discussions.

\section{Benefits to constituents}

The Portal to Texas History offers a variety of benefits to its core constituents: students, researchers, educators and teachers, and collaborative partners. Informal surveys conducted by the Portal staff indicate that students of Texas history could benefit from the inclusion of primary source materials in their curriculum. Access to interesting, unique and relevant materials carry learning beyond the strictures inherent in textbooks. Researchers will also 
benefit from the materials in the portal. Randolph B. Campbell, Regents Professor of History at UNT, and a noted authority on Texas history says:

For more than 30 years, I have researched and written in the field of Texas history, an endeavor that has required more trips to libraries and depositories around the state than I care to count. I also have taught seminars in Texas history for many years, and in every

case I had to recognize that my students could not gain access to many important materials unless they took long (this is Texas, after all) and expensive trips, which I could not ask of them. The Portal to Texas History project will bring essential material to the

fingertips of scholars and students in a readily usable format (Campbell, 2003).

Plans to include curriculum materials for students will benefit educators and assist them in their efforts in bringing an added-value educational experience to their pupils. Portal partners will also benefit in many ways: training opportunities and guidance on best practices, grant-seeking, and cost-recovery opportunities.

\section{Plans for the future}

As the Portal to Texas History increases its content, opportunities for value-added services abound. Some services will enhance the educational value of the available content and other services could assist with site sustainability. Additionally, recognizing the benefits of continued collaboration, the portal project manager is also leading a state-wide effort in conjunction with the Texas State Library and Archives Commission (www.tsl.state.tx.us/) to plan for interoperability and collaboration among already existing digitization efforts for Texan cultural heritage materials. The sections below address future plans related to the development of a business plan to assist with sustainability, creation of curriculum guides to enhance the educational value of the portal content, and continued formation of collaborative relationships.

\section{Business plans for sustainability}

Across the nation, digital projects find themselves increasingly challenged by the difficulties of sustainability. It is well established that grant funding and institutional budgets alone are insufficient to provide for the full costs of digitization. In turn, institutions look at models from the for-profit sector in implementing cost-recovery revenue streams to subsidize digitization efforts. The Council of Library and Information Resources publication, Business Planning for Cultural Heritage Institutions (Bishoff and Allen, 2004) points out the fallacies often seen in business planning in the non-profit sector, and emphasizes the importance of sound business practices, market studies, and strategic planning. The balance between the traditional mandates for institutions as educators and providers of cultural heritage materials and the goal of cost-recovery will be influenced by an organization's internal and external environment.

In conceptualizing the development of a business plan, the portal partners must consider the full range of resources and staffing that will be required to accomplish revenue producing goals 
- recognizing that a lack of sound planning can easily lead to failure. A June 2002 paper from the Higher Education Digitisation Service (HEDS) based at the University of Hertfordshire, Exploring Charging Models for Digital Cultural Heritage stated that, "on the whole, there is no real business planning and modeling in most institutions, and less than 30 percent of those interviewed had attempted to calculate or quantify the exact costs for creation, storage, or service provision of digital items" (Tanner and Deegan, 2002, p. 16). "There is however a marked lack of clear commercially-led business planning and control in most institutions surveyed ... charging policies are almost always based on the perceived market value (as defined by what similar organizations are charging) rather than the actual cost of provision" (Tanner and Deegan, 2002, p. 19). The report Building and Sustaining Digital Collections: Models for Libraries and Museums (Council on Library Information and Resources, 2001) also emphasized the need to incorporate existing business models without "reinventing the wheel".

The Portal to Texas History partners are developing a business plan that includes an innovative plural cost-recovery model for multiple revenue streams. The portal operates on a non-profit basis, with free public access to the contents, but cost-recovery projects that can fund equipment upgrades and offset other costs of digitization efforts remain vital. A formal business plan for the project will include possible revenue streams from:

- Digital conversion projects. In the 2003-2004 academic year, UNT began accepting work for digital conversion projects for outside institutions. Work included scanning, performing optical character recognition, proofreading, and XML mark-up of text. Important statistical and management data collected from these projects will be used to refine process and pricing models and to streamline workflow and management issues. Funds from these projects assisted with hardware and software purchases for UNT's digital laboratory.

- Clearinghouse for licensing of digital content. The partnership plans to serve as a clearinghouse for licensing the content of members interested in participating in this aspect of the plural cost-recovery model. Currently, commercial users researching images for a publication or exhibit must typically contact each institution and work through a confusing maze of differing reproduction licensing agreements, fees and paperwork in responding to the request. Pricing mechanisms would consider copyright, intended use, and service cost.

- Reproductions of historical items. Institutions have traditionally offered copies and reproductions from their collections, but the partnership plans to expand this service with an e-commerce solution. Users will be able to purchase either a high-quality digital image or hardcopy directly from the Portal to Texas History web site. Partners may select services that are in accordance with their institutional culture.

- Reprints of public domain books. The partnership between Historic Pittsburgh and North Haven Press represents a successful model for offering reprints of public 
domain books. The business plan will explore creating reprints of public domain books from the Portal collection, working either with the University of North Texas Press or another small printing house.

- Consulting. Several universities have approached the University of North Texas Libraries about providing consulting for digital projects unrelated to the Portal to Texas History. Potential clients have an interest in expert guidance, as well as turnkey solutions for digital databases. During the business planning process, this service will receive further study.

- On-demand printing. UNT currently engages in printing posters, maps, presentation materials, and other items for both internal and external customers. Analysis of data collected during the past year for costs of ink, paper, and staffing will enable optimal pricing strategies.

The portal partners plan to incorporate the e-commerce capabilities of the University's Enterprise Information System to provide e-commerce and accounting functions. Other software will be reviewed and selected to provide additional functionality, to include: project tracking, customer relationship management (CRM), enterprise resource planning (ERP), and collaborative groupware tools. Project tracking functions can generate hierarchic project trees and Gantt charts, and monitor pending tasks. E-commerce solutions provide bundle order and invoice management with payment processing. CRM provides a tool and business strategy that focuses on customer satisfaction, comprehensively tracking customer behaviors to better understand, anticipate, and appreciate their needs. ERP packages offer modules covering marketing and sales functions, production, inventory control, procurement, distribution, finance and accounting. Further plans include the development of a collaborative online workspace for all participants to use in developing membership criteria and business plan objectives. This collaborative workspace will comprise a groupware/virtual environment that allows real-time editing of content.

Should grant funding become available, the portal partners plan to consult with experts on evolving business models and e-commerce solutions to seek their assistance with the development of the portal's business plan. The partners recognize that a subject matter expert intimately involved with cutting-edge business methodologies should bring new and innovative perspectives to the creation of a business plan for sustainability.

\section{Curriculum materials for students}

As is true of many states, Texas requires its seventh-grade students to study state history, and many college students also study Texas history. Because history and culture studies textbooks would be enhanced by supplemental primary source materials, thousands of students and their teachers could benefit from the portal services and content. Planned portal services include: 
- teacher-only access to model curricula, created by teachers, for integrating portal services and resources into classroom activities and assignments;

- restricted access to specially created class resource sites where teachers, either individually or collaboratively, may place links to assigned materials and other information for the class(es), and students and teachers may then post discussion about the assignment; and

- support for innovative opportunities, such as interactions across school district boundaries for teachers and students that enhance student experiences and learning outcomes in history or culture studies.

An informal survey of educators revealed the need for quick and easy access to primary source materials about well-known events in Texas history, such as the Alamo or the annexation of Texas to the USA. Teachers and school librarians also cited a need for information on the local histories of their areas and to support studies about the Native Americans of Texas, explorers, and other famous historical leaders, while reflecting the broad cultural diversity of all Texans. To support these educational needs, content selections will focus on the desired subject areas, and training sessions will be created to instruct teachers and school librarians on the use of the supporting materials.

With funding from the Texas Telecommunications Infrastructure Fund grants and Microsoft Foundation grants, a strong majority of Texas schools and libraries now possess the technology to access online materials. US Secretary of Education Rod Paige notes that educators have been slow to truly embrace and integrate technology into learning curriculums. He says, "The way we organize schools and provide instruction is essentially the same as it was when our Founding Fathers went to school. Put another way, we still educate our students based on an agricultural timetable, in an industrial setting, yet tell students they live in a digital age" (Paige, 2002). The portal partners believe that the timing is right, and that the need exists for building partnerships among schools, libraries, and museums to make the primary-source content available on the web and to prepare teachers to integrate the portal services and resources into their classrooms in ways that will benefit student learning.

\section{Continued formation of collaborative relationships}

Currently, the Portal to Texas History project's institutional partners include museums, public libraries, and private collections. Recognizing that Texas encompasses a large geographic area with a diverse and rapidly growing population, the project partners believe that many additional institutions could benefit from a wider collaboration. Collaboration within the state of Texas could bring benefits in areas such as:

- Increasing interoperability among the several existing digital initiatives. Other state institutions are now sponsoring digitization efforts for Texan heritage materials, and 
the Texas State Library and Archive Commission's Library of Texas project could serve as a central point of access for a federated search of all such sites to greatly enhance access for users.

- Creating an online thesaurus for Texas history. Building a robust thesaurus, and a subsequent controlled vocabulary list, will not only aid in the organization and access of information within the portal, but also provide a valuable tool for students and researchers of Texas history of all ages. A thesaurus will aid in the classification and indexing of information objects for the creation of descriptive metadata records for the portal database. Terms will be generated to represent the broad aspects of Texas history, and as a means of providing subject headings and descriptive terminology. Possible sources for terms could include primary historical sources, existing reference works on Texas history, and the primary information objects contained within the Texas History Portal. Subject experts could provide the structural framework to place the generated terms in, along with choosing contemporary terms that relate to more antiquated terms from earlier literature. Subject experts will also help to balance the needs between the various user groups of the portal, by representing a broad cultural user base, which ranges from school-aged children, to college students, to history buffs and aficionados. A truly collaborative effort will provide a wealth of terms reflecting the depth of Texas history and heritage while enriching the educational life of all users.

- Sharing resources. Software, hardware, storage, bandwidth, and grant writers are some examples of resources that could be shared to benefit all members of a wider collaborative organization. For example, expensive scanners for specialized tasks might be purchased by the collaborative for use by all participating institutions, or grant writers in larger institutions might serve as resource persons and readers of draft proposals developed by small libraries and museums that do not have full-time development staff.

- Offering training opportunities. Collaborative planning for training to benefit persons in institutions across the state is an effective use of resources and ensures that participants stay abreast of evolving best practices and standards. Training ranging from basic scanning skills to advanced issues related to digital archiving could be provided. For example, tutorials created by one institution to teach best practices in basic scanning could be used by multiple institutions. Similarly, one workshop related to the Metadata Encoding and Transmission Standard (METS)

(www.loc.gov/standards/mets/) could accommodate interested persons from several institutions.

Recognizing the potential for further collaboration, the portal project manager initiated an effort, in partnership with the Texas State Library and Archives Commission, to bring together individuals from institutions across Texas for an initial meeting in May 2004, to talk about wider 
collaboration (www.library.unt.edu/digitalprojects/texdig/thdi.htm). More than 80 individuals attended this meeting representing public libraries, academic libraries, museums, archives, state agencies, state historical associations and commissions, publishers, and others. Speakers included Marsha Semmel, Director of Strategic Partnerships, Institute of Museum and Library Services, and Liz Bishoff, Vice President for Digital Collection and Preservation Services for OCLC and former director of the Colorado Digitization Program. Their collective wisdom - acquired from years of experience with collaborative projects - provided insight to participants pursuing further collaborations.

In her presentation, Semmel referred to a lecture, "No longer under our control: the nature and role of standards in the 21st Century Library", in which William E. Moen refers to standards building as "first and foremost a social process" (Moen, 2003, p. 5). Moen listed activities involved in the process of developing and creating a standard as: "Brainstorming, clarifying requirements, collaborative authoring, competitive collaboration, compromising, consensus building, developing proposals, editing, environmental scanning, information sharing/transfer, modeling, negotiating, planning, problem defining, problem resolving, problem solving, setting requirements, socializing, strategizing, visioning, and writing" (Moen, 2003, p. 5). Clearly, collaboration for digitization of cultural heritage materials is also driven by social processes and requires similar activities. With skilled programmers, technology can accommodate almost any collaborative architecture. The pitfalls lie in the social processes to reach agreement on collaborative architectures and then to sustain the agreements through development, implementation, and operation. To do this, benefits to participants must always outweigh the pitfalls.

\section{Conclusion}

Overall, the Portal to Texas History initiative strives to build on open source software and existing standards. All images and file structures are designed to support portability and future migration, independent of hardware and software. This flexible design should enable implementation of developing standards such as METS - a schema for encoding descriptive, administrative, and structural metadata for digital objects - and also allow compliance with OAI (Open Archives Initiative) harvestable metadata protocols and Z39.50 protocols for interoperability related to search and retrieval of information.

Brenda Gunn, head of archives and manuscripts at the Center for American History at the University of Texas at Austin, recently noted, "Most historical documents never receive one moment of attention outside of an archives reading room" (Gunn, 2004, p. 15). Materials stay in obscurity because potential users may not realize they exist or may not have the resources for physically visiting the holding institution. At the Portal to Texas History, we hope to transform this reality, enabling users to uncover treasures of history previously known only to an elite few. Digital libraries enable new styles of learning and scholarship, offering life-long learners access to a wealth of online materials. 


\section{References}

Alemneh, D.G., Hastings, S.K. and Hartman, C.N. (2002), “A metadata approach to preservation of digital resources: the University of North Texas Libraries' experience", First Monday, Vol. 7 No. 8, available at: www.firstmonday.dk/issues/issue7 8/alemneh/index.html (accessed 7 June 2004).

Bishoff, L. and Allen, N. (2004), Business Planning for Cultural Heritage Institutions, Council on Library and Information Resources, Washington, DC, available at:

www.clir.org/pubs/reports/pub124/pub124.pdf (accessed June 14, 2004).

Campbell, R.B. (2003), letter to the Institute of Museum and Library Sciences, Washington, DC.

Council on Library and Information Resources (2001), Building and Sustaining Digital Collections: Models for Libraries and Museums, The Council, Washington, DC, available at: www.clir.org/pubs/reports/pub100/pub100.pdf (accessed June 14, 2004).

Gunn, B. (2004), "Controversy in the archives: a documentary saga of Davy Crockett's death", Texas Library Journal, Vol. 80 No. 1, pp. 10-15. [Infotrieve]

Moen, W.E. (2003), "No longer under our control: the nature and role of standards in the 21st century library", Luminary Lectures @ your library ${ }^{\top M}$, Library of Congress, Washington, DC, available at: www.loc.gov/rr/program/lectures/moen.html (accessed June 14, 2004).

Paige, R. (2002), "Introductory letter", VISIONS 2020: Transforming Education and Training Through Advanced Technologies, US Department of Commerce, Technology Administration, Washington, DC, available at: www.technology.gov/reports/TechPolicy/2020Visions.pdf (accessed June 14, 2004).

Tanner, S. and Deegan, M. (2002), "Exploring charging models for digital cultural heritage: digital image resource cost efficiency and income generation compared with analog resources", University of Hertfordshire, Hertfordshire, available from:

http://heds.herts.ac.uk/mellon/HEDS charging models.pdf (accessed June 14, 2004). 